\title{
On Track to Become a Low Carbon Future City? First Findings of the Integrated Status Quo and Trends Assessment of the Pilot City of Wuxi in China
}

\author{
Carmen Dienst ${ }^{1}{ }^{*}$, Clemens Schneider ${ }^{1}$, Chun Xia ${ }^{1}$, Mathieu Saurat ${ }^{1}$, Thomas Fischer ${ }^{2}$ \\ and Daniel Vallentin ${ }^{1}$
}

1 Wuppertal Institute for Climate, Environment and Energy/Doeppersberg 19, Wuppertal D-42109, Germany; E-Mails: clemens.schneide@wupperinst.org (C.S.); chun.xia@wupperinst.org (C.X.); mathieu.saurat@wupperinst.org (M.S.); daniel.vallentin@wupperinst.org (D.V.)

2 National Climate Centre (NCC), China Meteorological Administration (CMA)/46 Zhongguancun Nandajie, Haidian, Beijing 100 081, China; E-Mail: tom.fischer8@ gmx.de

* Author to whom correspondence should be addressed; E-Mail: carmen.dienst@wupperinst.org; Tel.: +49-202-2492-203; Fax: +49-202-2492-198.

Received: 13 May 2013; in revised form: 11 July 2013 / Accepted: 12 July 2013 / Published: 31 July 2013

\begin{abstract}
The Low Carbon Future Cities (LCFC) project aims at facing a three dimensional challenge by developing an integrated city roadmap balancing: low carbon development, gains in resource efficiency and adaptation to climate change. The paper gives an overview of the first outcomes of the analysis of the status quo and assessment of the most likely developments regarding GHG emissions, climate impacts and resource use in Wuxi-the Chinese pilot city for the LCFC project. As a first step, a detailed emission inventory following the IPCC guidelines for Wuxi has been carried out. In a second step, the future development of energy demand and related $\mathrm{CO}_{2}$ emissions in 2050 were simulated in a current policy scenario (CPS). In parallel, selected aspects of material and water flows for the energy and the building sector were analyzed and modeled. In addition, recent and future climate impacts and vulnerability were investigated. Based on these findings, nine key sectors with high relevance to the three dimensions could be identified. Although Wuxi's government has started a path to implement a low carbon plan, the first results show that, for the shift towards a sustainable low carbon development, more ambitious steps need to be taken in order to overcome the challenges faced.
\end{abstract}


Keywords: Low Carbon Future Cities; low carbon city strategies; China; Wuxi; low carbon scenario; circular economy; adaptation; mitigation

\section{Introduction}

Cities have always been hot spots of innovations, but since the beginning of industrialization they have also faced severe environmental impact due to the high concentration of industries, population and infrastructures. Today, and in the coming decades, cities can also be seen as hot spots of greenhouse gas emissions, being areas most exposed to the impacts of climate change [1]. This is particular true for cities in developing regions, where the urbanization rate and number of industries is increasing at a high pace. According to the UN Habitat [1] about $40 \%$ to $78 \%$ of global greenhouse gas emissions are estimated to originate in urban areas.

Therefore, low carbon city strategies and concepts implicate large greenhouse gas (GHG) mitigation potential. At the same time, with high population and infrastructure densities, as well as concentrated economic activities, cities are particularly vulnerable to the impacts of climate change and need to adapt. Scarce natural resources further constrain the leeway for long-term, sustainable urban development.

\subsection{Background to LCFC Project}

This paper presents outcomes of the Sino-German Low Carbon Future Cities (LCFC) project. The aim of the project is to develop an integrated, urban, low carbon adaptation and circular economy strategy to address the large mitigation potential in urban areas by, and through, engaging cities and stakeholders in both China and Germany in an integrated approach. The study focuses on two pilot regions - one in China (Wuxi) and one in Germany (Düsseldorf) - and is conducted by a German-Chinese research team supported by the German Stiftung Mercator.

The purpose of the present study within the LCFC project was the analysis of the status quo and the assessment of the likely future development for the city of Wuxi, taking into account three project dimensions:

- greenhouse gas emissions and related mitigation potentials;

- vulnerability to climate change and adaptation options

- material and resource uses.

The outcomes of this study form the scientific basis for the development of LCFC strategy.

The study has been divided into five main working areas. The emission inventory gives an overview on the present relevant GHG emissions; it follows the IPCC-guidelines and uses data of the Wuxi statistical yearbook (WMBS) [2]. The results are inter alia basis and important criteria for the identification of key sectors relevant to policy, resource use (for energy and construction sector), vulnerability to climate change and future trends. The vulnerability to climate change in Wuxi was assessed by analysing recent climatic changes, and projecting expected changes in temperature and precipitation over the coming four decades. The future development of energy demand and related $\mathrm{CO}_{2}$ 
emissions in 2030 were simulated in the current policy scenario (CPS). This modeling approach uses five different sub-models and implies Wuxi's low carbon targets. Selected aspects of Wuxi's current material and water flows in the energy transformation sector and the buildings sector were investigated and modelled. After shortly describing the applied methodologies, the paper summarizes the results and provides first conclusions for decision-makers as well as for research.

\subsection{Background to Wuxi and Current Policy Approach}

The pilot city Wuxi is located in the East of China on the lower Yangtze River, about $130 \mathrm{~km}$ from Shanghai. Wuxi has a population of about six million and its economy has witnessed a considerable increase in recent years.

Wuxi is a regional hotspot of energy-intensive industry operations, especially for steel, iron and chemical production. The overall GDP was CNY 575.8 billion (EUR 64.3 billion) in 2010, double that of 2005 and with an average annual growth rate of 14\% (2006-2010). All these achievements make Wuxi's comprehensive strength and competitiveness rank high among large and medium cities in China.

The GDP per capita of Wuxi is high, resulting in relatively low carbon intensity. However, its relative emissions, i.e., $\mathrm{CO}_{2}$ per capita, are very high compared to Chinese average. Nonetheless, the Wuxi city government is an early mover in promoting low carbon development in China and has adopted several policy documents to emphasize this role. Among the key documents are the 12th Five Year Plans from 2011 (Low Carbon City Construction Plan; Energy Conservation Plan; Energy Development Plan). They are strategic documents that lay out the city's low carbon strategy in different sectors. An important target is to reduce $\mathrm{CO}_{2}$ emissions by $20 \%$ per unit GDP within the $12^{\text {th }}$ Five-Year Plan period (2011-2015). This means that Wuxi's carbon intensity target is three percentage points more ambitious than the national target, despite its strong dependence on energy-intensive industries. For 2020, the Wuxi government has committed itself to reduce the carbon intensity of the city's economy by $50 \%$ compared to 2005 .

Exemplified for specific sectors, the following future targets are set, e.g., the city government aims to alleviate the carbon footprint of the local industry by gradually phasing-out energy intensive enterprises and accelerating the development of a less carbon-intensive service sector. The heavily coal-reliant energy supply will be diversified through stopping further construction of coal-fired power plants and increasing natural gas utilization, as well as the usage of renewables in power and heat generation. These policies were taken into account for the future trend assessment.

\section{Methods}

For each project area-vulnerability to climate change; status quo and projection of greenhouse gas emissions, as well as analysis of resource use \& material flow in selected sectors - different groups of experts were involved, applying the most suitable models and methodologies for the analysis of their research questions within the study. A short description of the used methodology is given in the sub-sections below. The basis for this paper is detailed calculations and background reports, which have so far not been published [3]. 


\subsection{GHG Emissions-Inventory and Future Model}

\subsubsection{GHG Inventory}

Present $\mathrm{CO}_{2}$ emissions, and possibly other $\mathrm{GHG}$ emissions, have been quantified in an emission inventory for the Wuxi territory. Based on these figures and other criteria, the most important sectors on which to focus the in-depth study and measures, for low carbon city development in Wuxi, were identified.

A greenhouse gas inventory accounts for the amount of greenhouse gases emitted to or removed from the atmosphere due to human activities over a specific period of time.

Quantification of greenhouse gas emissions for inclusion in an inventory is a multi-step process which includes: (a) the identification of all anthropogenic greenhouse gas sources and sinks; (b) the selection of measurement, calculation or estimation approaches; (c) the selection and collection of activity data; (d) the selection or development of greenhouse gas emission or removal factors; (e) the application of calculation methodologies to quantify greenhouse gas emission and/or removal [4].

In this study, the inventory methodology outlined in the 2006 IPCC guidelines on GHG inventories [5] was followed in a simplified and adapted manner. The inventory is divided into four main sectors: (1) Energy (including all energy-related emissions, also from the industry); (2) Industrial Processes and Product Use (IPPU) (including only the process-related emissions, not the energy-related); (3) Agriculture, Forestry and Other Land Use (AFOLU) and Waste.

The study focused on $\mathrm{CO}_{2}$ emissions, other GHGs were considered only to a lesser extent depending on available data. According to IPCC, the so-called "territory principle" was followed, meaning that GHG emissions were allocated to the territory where they were emitted. Up-stream life-cycle emissions from products not produced in the territory were not counted as its emissions in the inventory. Life-cycle emissions and material use of specific sectors are analysed in the work on resource use (see Section 2.4).

The inventory is largely based on Wuxi's statistical yearbook [2], and information and data provided by Chinese project partners - especially the Wuxi Low Carbon Development and Research Centre (WLCC) and the Wuxi city government.

\subsubsection{Current Policy Scenario}

The CPS shows the development of energy demand and energy related $\mathrm{CO}_{2}$ emissions in Wuxi until 2050. The scenario has considered today's (2011) political framework (based on the "Wuxi Low Carbon City Development Plan") and a set of assumptions about the development of the city's society, economy and infrastructure (see below).

The CPS was developed by using a complex simulation modeling approach. This approach can be described as a model framework, consisting of one core model and five sub-models (see Table 1). The core model named Wuxi CESS Model (CESS = City Energy System Simulation) is an energy system simulation model and has been developed by the Wuppertal Institute (WI). The Wuxi CESS Model's database is linked to five sub-models (Industry, Buildings, Household appliances, Service Sector, Transport and Power \& Heat sub-model). They provide activity data, market shares and mean efficiencies of technologies. The industry sub-model, as one of the five sub-models, is part of an independent econometric energy system model developed by China Environment Research (CER). 
The other sub-models have been designed as disaggregated technology-based simulation models to account for the use of low carbon (LC) technologies, which is intended to be part of forthcoming low carbon scenarios for Wuxi. The building sub-model has been developed by experts of the Research Centre for International Environmental Policy (RCIEP) at the Tsinghua University in Beijing, the other sub-models have been developed by the WI (see table below).

The CPS employs a bottom-up approach, nevertheless taking into account some key global socio-economic data and political and economic framework conditions. Accordingly, the developments in the sectors are outlined independently without considering any optimization of the energy system in Wuxi.

Table 1. Overview of the sub-models used in the Current Policy Scenario (CPS).

\begin{tabular}{|c|c|c|c|}
\hline & System Boundary of the Sub-Model & $\begin{array}{l}\text { Model Components and } \\
\text { Modeling Approach }\end{array}$ & Developer \\
\hline Industry sub-model & $\begin{array}{l}\text { Energy use of all single branches } \\
\text { of industry }\end{array}$ & $\begin{array}{l}\text { Econometric approach based on } \\
\text { historical energy and gross value } \\
\text { added data }\end{array}$ & CER \\
\hline Buildings sub-model & $\begin{array}{l}\text { Floor areas (square metre) of rural } \\
\text { and urban residential buildings and } \\
\text { public buildings; electricity use for } \\
\text { heating/cooling, hot water and } \\
\text { lighting, respectively }\end{array}$ & $\begin{array}{l}\text { Simulation approach based on } \\
\text { space (square metre) }\end{array}$ & RCIEP \\
\hline $\begin{array}{l}\text { Household appliances } \\
\text { sub-model }\end{array}$ & $\begin{array}{l}\text { Electricity demand of electric } \\
\text { appliances in private households }\end{array}$ & $\begin{array}{l}\text { Simulation approach based on the } \\
\text { number of appliances }\end{array}$ & WI \\
\hline $\begin{array}{l}\text { Service Sector sub-model } \\
\text { (without buildings) }\end{array}$ & $\begin{array}{l}\text { Electricity demand of the service } \\
\text { sector other than for heating/ } \\
\text { cooling, hot water and lighting. }\end{array}$ & $\begin{array}{l}\text { Simplified forecasting according } \\
\text { to the electricity demand of } \\
\text { commercial buildings }\end{array}$ & WI \\
\hline Transport sub-model & $\begin{array}{l}\text { Energy use for transport carried out } \\
\text { by Wuxi population and carriers }\end{array}$ & $\begin{array}{l}\text { Stock Exchange (vintage) Model } \\
\text { for } 11 \text { highway vehicle types and } \\
\text { for public transport (bus and } \\
\text { subway trains) }\end{array}$ & WI \\
\hline Power \& Heat- sub-model & $\begin{array}{l}\text { Fuel use in power and heat } \\
\text { plants as well as combined heat } \\
\text { and power plants (CHP) } \\
\text { (within the Wuxi territory) }\end{array}$ & $\begin{array}{l}\text { Stock Exchange (vintage) Model } \\
\text { for single power plants in Wuxi }\end{array}$ & WI \\
\hline
\end{tabular}

The sectors simulated (industry, commerce, households, transport and energy supply) follow the same structure as the GHG inventory, but are not entirely consistent with the IPCC inventory sub-classification. All sector sub-models are linked to the power and heat sub-module.

\subsection{Activity Data and Assumptions}

\subsubsection{Activity Data}

The most important data source for this study was the Statistical Yearbook of Wuxi, from the Wuxi Municipal Bureau of Statistics [2]. Although the statistical yearbook provides extensive data, which is 
exceptional at the city level, the gap between data available and data required for the inventory and the projection models is still high. In particular, for the industry sector only statistical data for "above-designated-size" industries were available.

"Above-designed-size enterprises" refer to those with an annual prime operating revenue exceeding CNY 5 million. From 2011, the "above-scale enterprises" will cover those with annual prime operating revenue bigger than CNY 20 million, which will reduce the available data and slightly increase the uncertainty of the results. Moreover, in country-wide statistics and in the city statistics (like the one of Wuxi), the processes within industry and applied technologies are normally not reported. This is a global challenge for inventory reporting.

In addition to these aspects, the available statistical data itself always has uncertainties. A study that was recently undertaken by a group of scientists from China, Britain and the United States analyzed different sets of Chinese statistical data. One set was based on nationwide data, the other on data from 30 provinces (for the years 1997-2010). The comparison showed that there are large differences between the data, which could lead to a gap of up to 1.4 billion tons of $\mathrm{CO}_{2}$ emissions (for 2010) between the datasets for the same area [6,7].

The results presented in the following sections are based on the activity data available, as well as on different models and methodologies, such as calculation factors and simulation models. For each of the future models, specific assumptions for the conditions in the future had to be considered in order to apply the models. This limits in fact the possible options for future development to these conditions, which is a simplification of the future prospects, so projections can always be seen only as one theoretical possible future development, which will in fact never become reality in exactly the same way.

\subsubsection{Assumptions}

Box 1 provides a narrative of the situation and development in the city until 2050.

Box 1. Wuxi 2050 - the storyline in a nutshell.

- Wuxi 2050 is a prosperous municipality: the economy faces demographic problems, but productivity is increasing.

- The city is still an industry hot-spot and plays an important role in the Chinese economy.

- The economy is undergoing structural changes in favor of the tertiary sector and non-energy intensive industries.

- The existing energy-intensive industries are not profitable, as they are not energy efficient.

- Households are equipped according to energy standards in developed Asian countries.

- $\mathrm{CO}_{2}$-intensity is declining.

- Absolute $\mathrm{CO}_{2}$ emissions rose sharply at the beginning of the century and have been stable since 2035 .

For the future economic development, in parts estimations from the NDRC Energy Research Institute (ERI) on the development of the outputs of major industrial products in China were considered [8] in order to extrapolate Wuxi's industrial production. Table 2 shows the basic assumptions on sociodemographic development of the city until 2050. Furthermore, the Wuxi Low Carbon City Development Plan represents the political framework for the scenario until 2020. The plan's aim is to 
reduce $\mathrm{CO}_{2}$ Intensity $\left(\mathrm{CO}_{2}\right.$ emissions per GDP) by 50\% in 2020, in comparison with the 2005 level. For the period after 2020, sectoral carbon intensity reductions in relation to gross value added of the industry sector in comparison with the 2005 level were assumed (i.e., 2030: 65\%; 2040: 70\%; 2050: $75 \%$ ). In the other sectors the moderate climate policy targets are reflected by moderate efficiency development in all technologies and a partial fuel switch from coal and oil to gas (electricity generation and industry) and electricity (transport).

Table 2. Basic socio-economic data for all scenarios.

\begin{tabular}{|c|c|c|c|c|c|c|c|}
\hline & Unit & 2009 & 2020 & 2030 & 2040 & 2050 & $\begin{array}{c}2009 \%-2050 \% \\
\text { Growth p.a. }\end{array}$ \\
\hline Permanent population & 1,000 & 6,245 & 6,731 & 6,598 & 6,325 & 5,826 & $-0.2 \%$ \\
\hline Urban districts & 1,000 & 3,448 & 4,473 & 4,822 & 4,858 & 4,743 & $0.8 \%$ \\
\hline Rural & 1,000 & 2,796 & 2,258 & 1,776 & 1,467 & 1,083 & $-2.3 \%$ \\
\hline Households & 1,000 & 2,062 & 2,404 & 2,399 & 2,343 & 2,158 & $0.1 \%$ \\
\hline Urban districts & 1,000 & 1,145 & 1,598 & 1,754 & 1,799 & 1,756 & $1.0 \%$ \\
\hline Rural & 1,000 & 917 & 806 & 646 & 543 & 401 & $-2.0 \%$ \\
\hline Working force & 1,000 & 5,114 & 5,040 & 4,803 & 4,187 & 3,893 & $-0.7 \%$ \\
\hline GDP* (real) & Mill. $\mathrm{RMB}^{++}{ }_{2005}$ & 452,175 & $1,138,622$ & $2,300,540$ & $3,758,442$ & $5,360,192$ & $6.2 \%$ \\
\hline Primary sector & Mill. $\mathrm{RMB}_{2005}$ & 8,481 & 14,217 & 17,970 & 21,186 & 23,775 & $2.5 \%$ \\
\hline Secondary sector & Mill. $\mathrm{RMB}_{2005}$ & 256,933 & 615,347 & $1,143,216$ & $1,659,976$ & $2,116,632$ & $5.3 \%$ \\
\hline Tertiary sector & Mill. $\mathrm{RMB}_{2005}$ & 186,761 & 509,057 & $1,139,355$ & $2,077,280$ & $3,219,784$ & $7.2 \%$ \\
\hline Productivity & $\begin{array}{c}1,000 \mathrm{RMB}_{2005} / \\
\text { work- force }\end{array}$ & 99 & 230 & 487 & 913 & 1,401 & $6.7 \%$ \\
\hline
\end{tabular}

Source: Calculation of population by CER/WI according to the development in Jiangsu Province [9]. Specific calculation of urban and rural population and their number of households, as well as GDP, according to [8]. * Gross Domestic Product; ** Million Renminbi (inflation-adjusted).

\subsection{Vulnerability to Climate Change and Adaptation Aspects}

The vulnerability to climate change in Wuxi was assessed by analysing recent climatic changes and by projecting expected changes in temperature and precipitation for this century. Special attention was devoted to water-related risks and possible economic losses. Based on these findings, sectors which are particularly vulnerable to climatic changes were identified.

The National Climate Center (NCC) of the China Meteorological Administration (CMA) conducted this assessment. They used the most comprehensive set of climate data available for Wuxi in order to analyses observed and projected changes in climatic parameters that are relevant to the identified weather and climate hazards. Daily climate parameters for seven meteorological stations in Wuxi were used in order to identify and describe changes for the period from 1961 to 2009 [10]. Suitable climate change indices, which primarily focus on extreme events, were developed. The same parameters were used for climate projections until 2100. These are based on an ensemble of three General Circulation Models (GCMs): ECHAM5/MPI-OM (General Circulation Model European Center Hamburg/Max Planck Institute-Ocean Model, 5th generation of the model version) [11], CSIRO-MK3.5 (3rd generation of the Commonwealth Scientific and Industrial Research Organisation Climate Model Mark 3.5) [12], 
and NCAR CCSM3 (National Center for Atmospheric Research Community Climate System Model version 3).

\subsection{Resource Utilization}

Selected aspects of resource use and flows in Wuxi, which are relevant for its low carbon development strategy, were investigated and modeled. The system boundaries for a complete assessment of Wuxi's resource efficiency ought to be those between Wuxi's technosphere (the socioeconomic system within the geographical boundaries) and the ecosphere (the natural environment worldwide). In terms of flows, it means that all natural resource inputs (direct or indirect, economically used or unused, domestic or foreign) that are activated by human activities in Wuxi-including through trade - have to be accounted for.

Two methods taken from a wider material flow analysis (MFA) toolbox were principally applied: material input per unit of service (MIPS) and economy-wide material flow analysis (EW-MFA). The first one, MIPS, focuses on the input side of the life cycle inventory of a studied product or process and accounts for economically non-valued resource extraction $[13,14]$. The latter method, EW-MFA, covers all material flows of the studied region.

It was beyond the scope of the study to consider resource use of Wuxi's entire socio-economic system. Thus, the analysis concentrated on selected sectors that: (a) have high relevance for the resource intensity and absolute resource use today; (b) had been identified as potential key sectors based on the GHG inventory; (c) will be targeted by mitigation and adaptation measures drafted in further work of the low carbon future city project.

The two selected key sectors that fulfilled these criteria were the "electricity and heat production sector (energy industry sector 1A1a)" and the "construction sector (focusing on residential buildings)". Aspects of material flow linked to the construction sector are of especial interest and are therefore described in the results and discussion section.

\section{Results and Discussion}

\subsection{Emission Inventory}

The main source for Wuxi's emissions is the combustion of raw coal, which is needed to meet the high demand for energy. Electricity and heat production are main sources of emissions, representing more than half of the current carbon dioxide emissions (39 million tons $\mathrm{CO}_{2}$ ). The total $\mathrm{CO}_{2}$ emissions of the energy, manufacturing industry and transport sectors (calculated at almost 72 million tons $\mathrm{CO}_{2}$ in 2009-see Figure 1 sum up to about a fourth of the corresponding $\mathrm{CO}_{2}$ emissions of the industrial center of Germany North Rhine-Westphalia or the total $\mathrm{CO}_{2}$ emissions of the country Chile. In the manufacturing industries' energy-intensive branches, like the iron and steel industry, and the chemical industry, are currently most relevant for the total $\mathrm{CO}_{2}$ emissions, but other sectors also have considerable emissions (see Figure 2, Table 3 and section on key sectors). Although we intended to analyze and integrate all "Kyoto" greenhouse gases, the data availability did not allow for a complete calculation. Thus, for non- $\mathrm{CO}_{2}$ emissions and non-energy related $\mathrm{CO}_{2}$ emissions, qualitative assumptions or process descriptions have been given. As Wuxi hosts several industries with potentially 
high process-related emissions, the current total emissions are higher than the figures calculated in the inventory. For agriculture only some exemplified sub-sectors have been calculated.

Figure 1. Total $\mathrm{CO}_{2}$-emissions (in million tons) of IPCC sectors 1A1-1A3 (energy-related emissions), divided into sub-sectors.

\section{$\mathrm{CO}_{2}$ emissions of total energy sector in Wuxi (2009) in Mio. $t$}

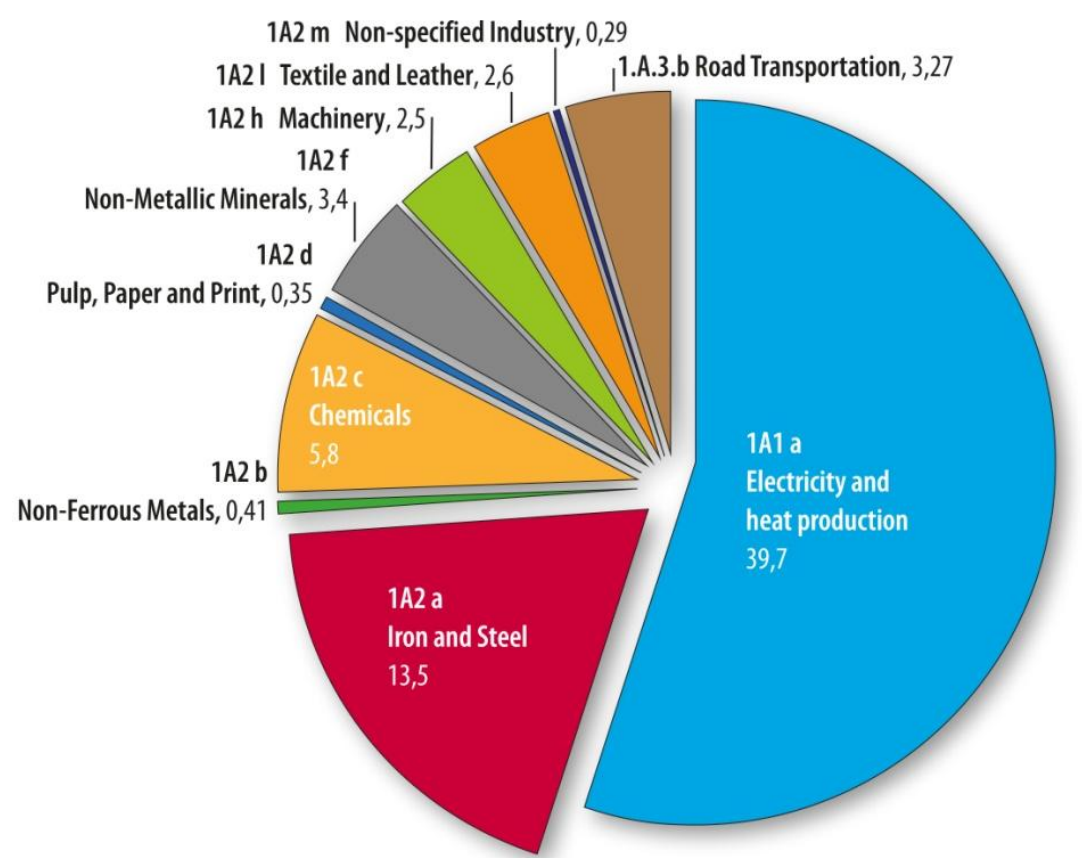

Figure 2. Development of energy-related $\mathrm{CO}_{2}$ emissions (in kilotons $\mathrm{CO}_{2} ;$ 2003-2009) in Wuxi of some relevant sectors in the energy industry (1A1), manufacturing industry (1A2) and transport sector (1A3).

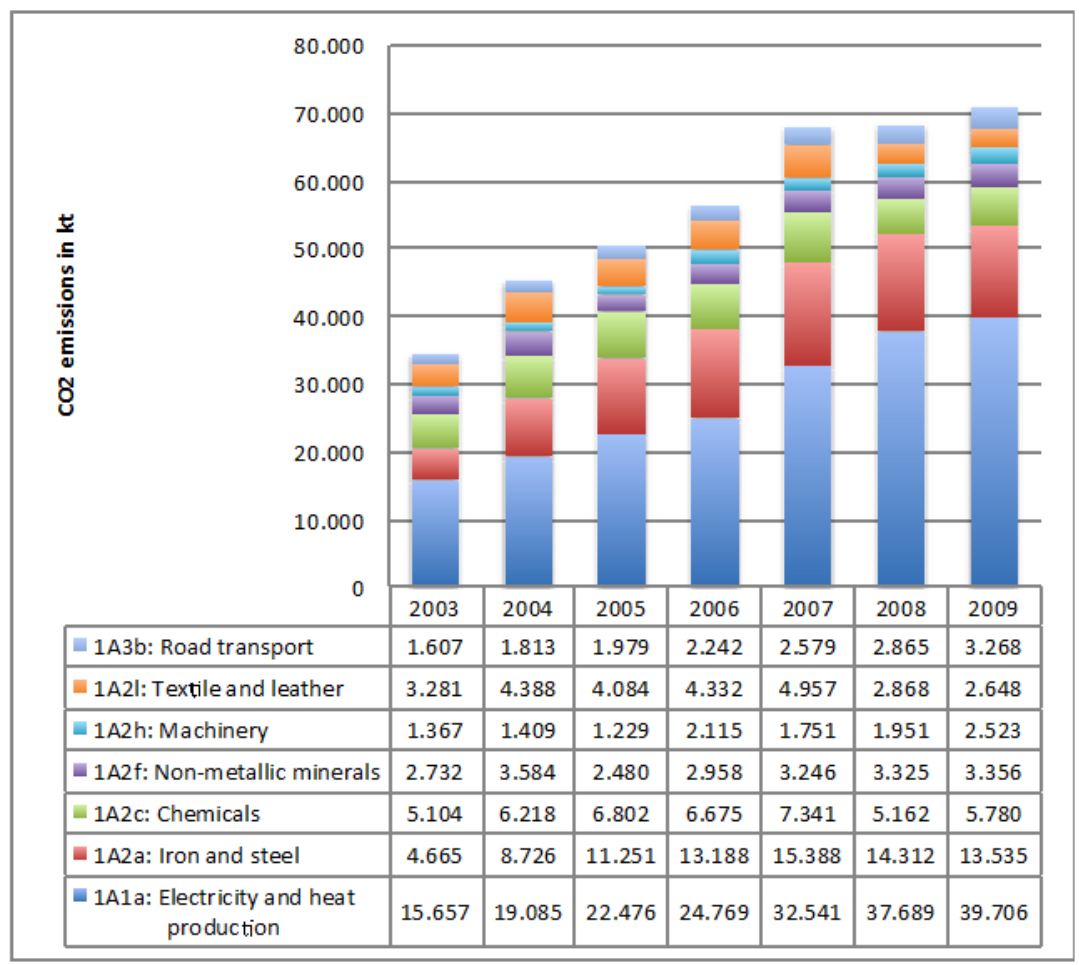


Due to the lack of appropriate activity data, emissions from waste disposal have so far not been calculated. However, waste could be a relevant source of emissions in Wuxi and also a sector with high mitigation potential. Thus, for future emission monitoring work of Wuxi experts, the data availability of this sector should be modified.

Thus, high improvement potentials are given for future inventory work. On the other hand it has to be stated that the data sources for Wuxi are already been very detailed compared to other cities around the world (including in comparison to European cities).

\subsection{Key Sectors Identified}

Sectors with high present and future $\mathrm{CO}_{2}$ emissions, a high impact on the environmental performance of Wuxi and high mitigation potentials were selected as key sectors to be addressed in detail in the process of strategy development. The key sectors in the pilot cities were selected in the course of a research and dialogue process among the project partners. For the identification of most relevant sectors, four aspects have been taken into account. According to the focus on low carbon and mitigation, one criterion is the current greenhouse gas emissions and future trends (based on the inventory and CPS). The relevance for political planning in the Wuxi municipality has also been considered as an important factor. Besides the mitigation dimension, climate change impacts were also taken into account, as well as the aspects of material and resource use according to the three dimensional approach.

Table 3. Total greenhouse gas emissions of all Intergovernmental Panel on Climate Change (IPCC) sectors $\left(\mathrm{CO}_{2}, \mathrm{CH}_{4}\right.$ and $\left.\mathrm{N}_{2} \mathrm{O}\right)$ in $\mathrm{CO}_{2}$ eq; Key sectors.

\begin{tabular}{|c|c|c|c|c|c|}
\hline $\begin{array}{l}\text { IPCC Guidelines } 2006 \text { - Sectors } \\
\text { (Summary of sectors) }\end{array}$ & $\begin{array}{c}\mathrm{CO}_{2} \\
\text { emissions }\end{array}$ & $\begin{array}{c}\% \text { of } \\
\text { sector } \\
\text { emissions }\end{array}$ & $\begin{array}{l}\text { Other GHG } \\
\text { emissions * }\end{array}$ & $\begin{array}{c}\text { Change } \\
\text { since } \\
2005\end{array}$ & $\begin{array}{c}\text { Key } \\
\text { sector }\end{array}$ \\
\hline Total Emissions and Removals & million tons & & million tons $\mathrm{CO}_{2} \mathrm{e}$ & & \\
\hline 1 ENERGY & 72.4 & & & & \\
\hline 1A1 Fuel Combustion Activities & 39.7 & & 0.200 & & \\
\hline 1A1a Electricity and heat prod. & 39.7 & & 0.200 & $\uparrow$ & ++ \\
\hline 1A1b Petroleum Refining & NE & & NE & & $?$ \\
\hline $\begin{array}{l}\text { 1A1c Manufacture of Solid } \\
\text { Fuels }\end{array}$ & & & NE & & $?$ \\
\hline 1A2 Manufacturing Industries & 29.0 & & 0.200 & & \\
\hline 1A2a Iron and Steel & 13.5 & $46.7 \%$ & 0.091 & $\pi$ & ++ \\
\hline 1A2b Non-Ferrous Metals & 0.41 & $1.4 \%$ & 0.003 & & \\
\hline 1A2c Chemicals & 5.8 & $19.96 \%$ & 0.041 & $\rightarrow$ & ++ \\
\hline 1A2d Pulp, Paper and Print & 0.35 & $1.2 \%$ & 0.003 & & \\
\hline 1A2e Food Processing etc. & 0.07 & $0.24 \%$ & $<0.001$ & & \\
\hline 1A2f Non-Metallic Minerals & 3.4 & $11.6 \%$ & 0.023 & $\pi$ & ++ \\
\hline 1A2g Transport Equipment & 0.10 & $0.34 \%$ & $<0.001$ & & \\
\hline 1A2h Machinery & 2.5 & $8.7 \%$ & 0.017 & $\pi$ & + \\
\hline 1A2j Wood and Wood Products & 0.01 & $0.03 \%$ & $<0.001$ & & \\
\hline 1A2k Construction & NE/ND (!) & & NE/ND (!) & & + \\
\hline 1A2I Textile and Leather & 2.6 & $9.1 \%$ & 0.019 & $y$ & + \\
\hline
\end{tabular}


Table 3. Cont.

\begin{tabular}{|c|c|c|c|c|c|}
\hline $\begin{array}{l}\text { IPCC Guidelines } 2006 \text { - Sectors } \\
\text { (Summary of sectors) }\end{array}$ & $\begin{array}{c}\mathrm{CO}_{2} \\
\text { emissions }\end{array}$ & $\begin{array}{c}\% \text { of } \\
\text { sector } \\
\text { emissions }\end{array}$ & $\begin{array}{l}\text { Other GHG } \\
\text { emissions * }\end{array}$ & $\begin{array}{l}\text { Change } \\
\text { since } \\
2005\end{array}$ & $\begin{array}{l}\text { Key } \\
\text { sector }\end{array}$ \\
\hline 1A2m Non-specified Industry & 0.29 & $1.0 \%$ & 0.002 & & \\
\hline 1 A3 Transport & 3.5 & & & & \\
\hline 1A3a Civil Aviation & $(0.18) * *$ & $5.0 \%$ & NE & $\uparrow$ & \\
\hline 1A3b Road Transportation & 3.27 & $92.8 \%$ & $\mathrm{NE}$ & $\pi$ & ++ \\
\hline 1A3d Water-borne Navigation & 0.08 & $2.2 \%$ & $\mathrm{NE}$ & & \\
\hline \multicolumn{6}{|l|}{ 1A4 Other Sectors } \\
\hline 1A4a Commercial/Institutional & IE $* * *$ & & & $\uparrow$ & + \\
\hline $\begin{array}{l}\text { 1A4b Residential (only gas } \\
\text { appliances }\end{array}$ & $\mathrm{IE}(+0.22) * * *$ & & $<0.001$ & $\uparrow$ & ++ \\
\hline \multicolumn{6}{|l|}{$\begin{array}{l}2 \text { INDUSTRIAL PROCESSES } \\
\text { AND PRODUCT USE (non- } \\
\text { energy) }\end{array}$} \\
\hline 2A Mineral Industry & NE/ND (!) & & & & ++ \\
\hline 2B Chemical Industry & NE/ND (!) & & NE/ND (!) & & + \\
\hline 2C Metal Industry & NE/ND (!) & & & & ++ \\
\hline $\begin{array}{l}\text { 2D Non-Energy Products from } \\
\text { Fuels and Solvent Use }\end{array}$ & NE/ND (!) & & NE/ND (!) & & \\
\hline 2E Electronics Industry & NE/ND (!) & & NE/ND (!) & & $?$ \\
\hline $\begin{array}{l}\text { 2F Product Uses /Substitutes } \\
\text { Ozone Depleting Substances }\end{array}$ & NE/ND (!) & & NE/ND (!) & & $?+$ \\
\hline $\begin{array}{l}3 \text { AFOLU (Agriculture, Forestry } \\
\text { and Other Land Use) }\end{array}$ & & & 0.881 & & \\
\hline 3A1 Enteric Fermentation & 0.031 & & 0.031 & & \\
\hline 3A2 Manure Management & --- & & 0.002 & & \\
\hline 3B Land (Rice cultivation) & --- & & 0.848 & & \\
\hline 4 Waste & --- & & NE/ND (!) & & $?$ \\
\hline
\end{tabular}

"NE/ND (!)" not estimated due to not available data/factors; "NE" not estimated; "NO" not occurring in the specific; "---" not applicable; "IE" included elsewhere; $(++)$ high relevance \& key sector; $(+)$ middle relevance; (?) possible relevance; * so far only $\mathrm{CH} 4 \& \mathrm{~N} 2 \mathrm{O} ; * *$ emissions of air passenger transportation, put in brackets as mainly occurring outside city boundaries; *** electricity use included in electricity production; use of natural gas \& LPG for cooking in residential sector.

An identification of important sectors is given in Table 3, differentiated by sectors with high relevance, the most dominant is electricity and heat production within the energy sector, which is responsible for more than half of the calculated $\mathrm{CO}_{2}$ emissions, deriving from the combustion of coal. During the analyzed period of 2003 to 2009, emissions more than doubled, from 15.7 to 39.7 million tons. The importance of the energy sector has already been reflected in Wuxi's $12^{\text {th }}$ Five-Year Energy Conservation Plan, but still — reflecting the results of the CPS (3.4.) - the emissions of the electricity production are very likely to increase further in the future, due to the high increase of the final energy demand.

Most of the remaining of the key sectors are industry sectors, like the iron and steel industry, the chemical industry, non-metallic minerals (cement), as well as electric equipment and machinery manufacturing. The iron and steel industry particularly stands out, which is why Wuxi has a specific 
$12^{\text {th }}$ Five-Year Plan on iron and steel industry development, aiming to bring the energy saving and environmental protection of Wuxi's industry to the international level.

The enormous increase of road transport, its related emissions, air pollution and future infrastructure challenges, makes it a key sector to be considered for Wuxi's intended low carbon future development.

Although for some sectors the direct GHG emissions within the city boundaries of Wuxi were not significant in the inventory, due to other relevant aspects they were also considered key sectors. This is true for the construction sector, which is an important sector due to the high material uses, further planned constructions, relatively short lifecycle of buildings compared to Europe, and the increasing electricity needs for room cooling and heating purposes. This aspect also has relevance for adaptation needs, due to increasing temperatures and living standards. Linked to the construction of buildings are the residential and the commercial (service) sectors, which are facing highly increasing electricity needs mainly due to increase of living standards and air conditioning needs, which should therefore also be regarded as two relevant key sectors.

\subsection{Changes in Climate Parameters and Vulnerability Aspects}

The vulnerability to climate change in Wuxi has been assessed by analyzing recent climatic changes and by projecting expected changes. For the period from 1961 to 2009, data from seven meteorological stations in Wuxi were used, and the projections until 2100 were based on an ensemble of three General Circulation Models (GCMs).

The results show that in the last 50 years all temperatures increased. While the minimum temperature increased in almost all months, the increases in maximum temperature mainly occurred in summer and autumn. For the changes in precipitation, it can be summarized that April and September became drier and January became wetter.

In the future, the temperatures are projected to further increase in each month at least until 2099, whereas the increase in summer is lower than during winter. Heavy and very heavy rain days are projected to increase non-significantly. The highest changes in climatic parameters (both observed and projected) were detected for frost days (decreasing, see Figure 3), summer days (increasing), warm spells (increasing, Figure 4), and cold spells (decreasing). Water levels did not exhibit a changing trend, and no changes in the water balance are expected for the coming decades.

Figure 3. Annual number of frost days observed (left) and projected (right) for Wuxi.

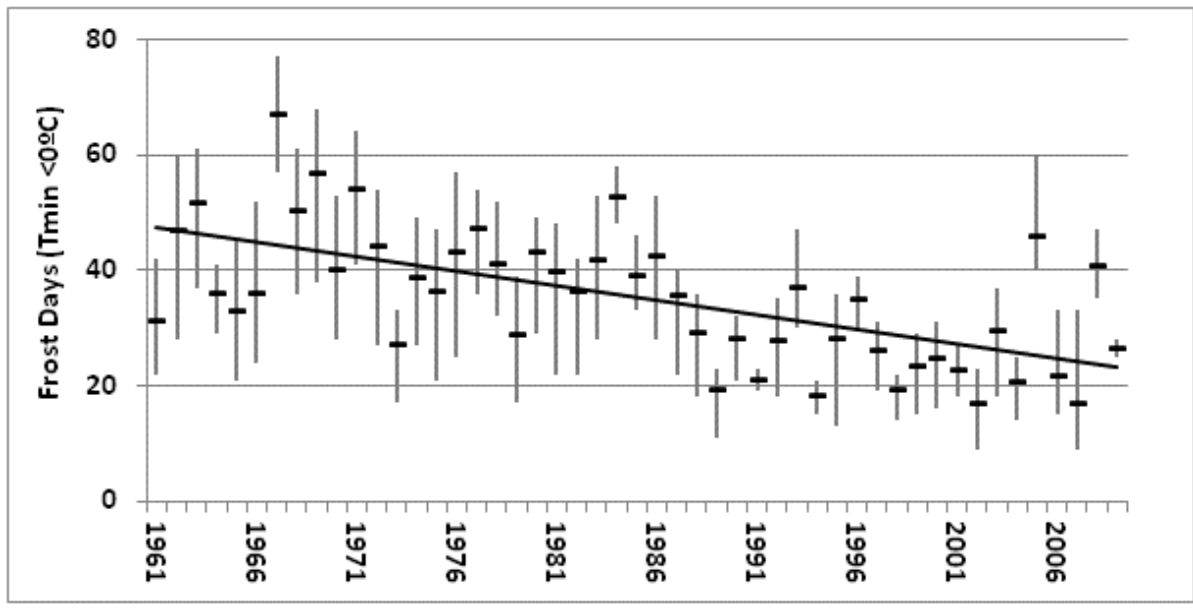


Figure 3. Cont.

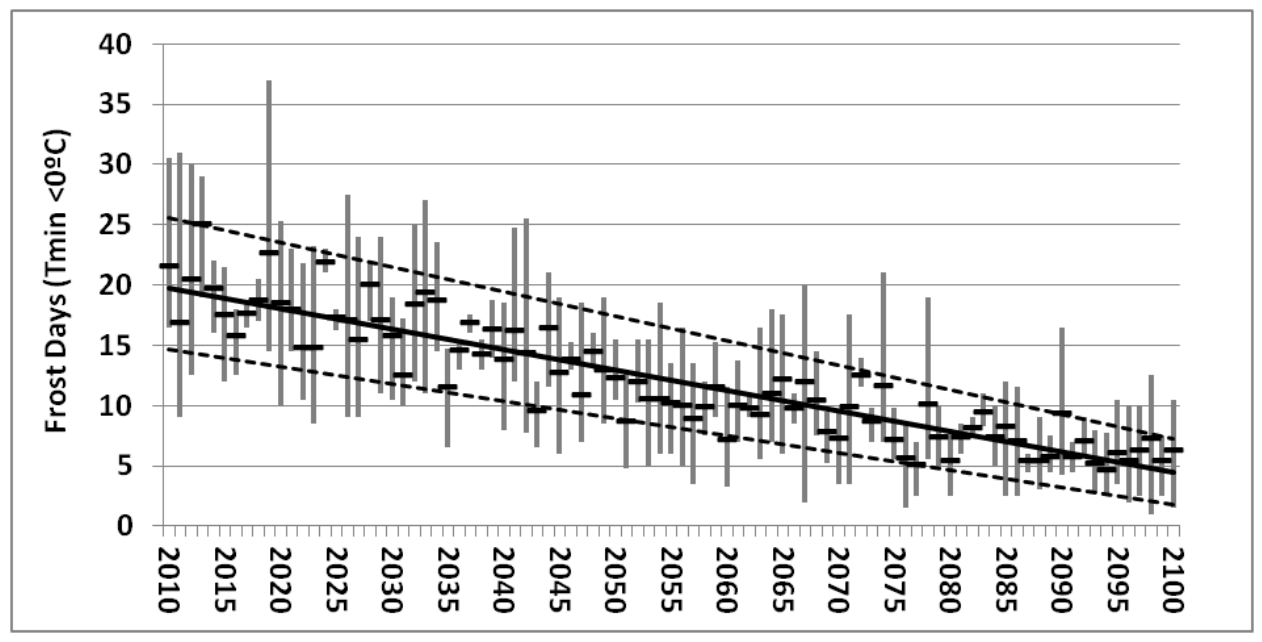

Figure 4. Annual warm spell duration observed (left) and projected (right) for Wuxi.

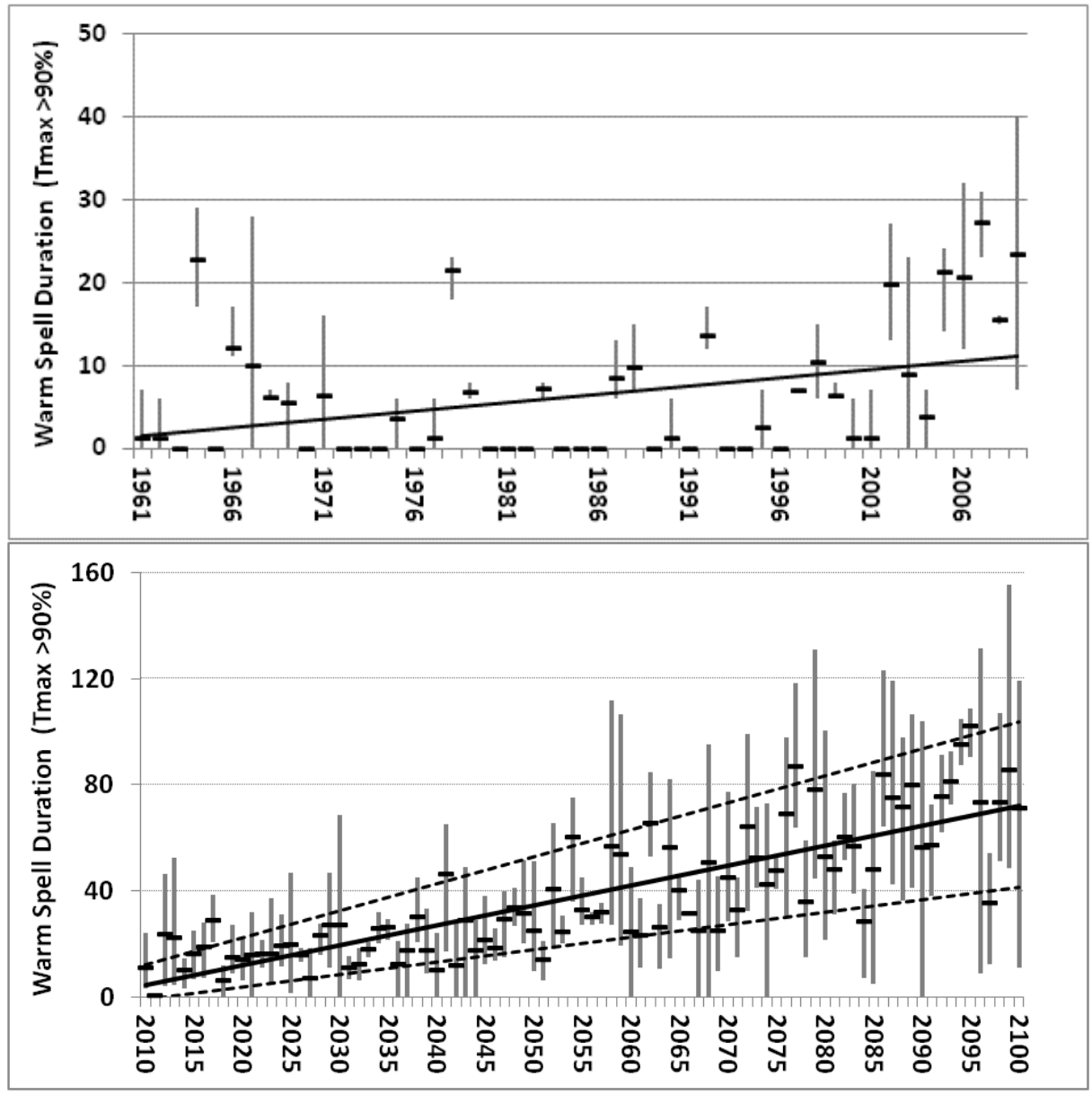

For Wuxi's vulnerability (coping capacity $\times$ damage potential), it is assumed that the risk will increase due to higher damage potentials, especially for floods/rain and temperature. More details on the recent and future developments in Wuxi can be found in the background paper [8]. 


\section{4. $C P S$}

The future development of energy demand and related $\mathrm{CO}_{2}$ emissions in 2030 were simulated in the CPS, using five different sub-models as described in Section 2.1.2. The assumptions were made in accordance with Wuxi's Low Carbon Plan (set targets until 2020) while for the later decades national scenario values were translated into a local $\mathrm{CO}_{2}$ intensity reduction path.

The Wuxi government has committed itself to reduce the carbon intensity of the city's economy by $50 \%$ by 2020 compared to 2005 . For the time after 2020 we assumed, in the CPS, that carbon intensity of industry will develop according to the whole economy's development in the baseline scenario of the ERI [6] study (2030:-65\%; 2040:-70\%; 2050:-75\%).

Figure 5. Energy carrier structure in Wuxi's industry 2005-2050. Source: Wuxi Statistical Yearbook [2], China Environment Research (CER)/Wuppertal Institute (WI)(projection).

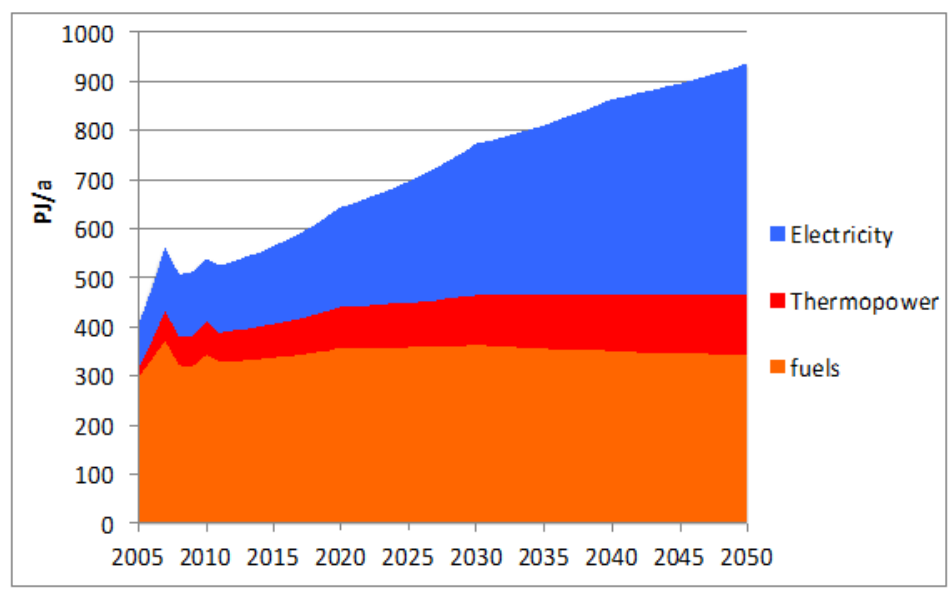

Mainly due to economic growth, the final energy demand in the CPS is expected to grow by $86 \%$ (2050 compared to 2009), which can be seen in Figure 6.

Figure 6. Development of final energy demand in the Current Policy Scenario.

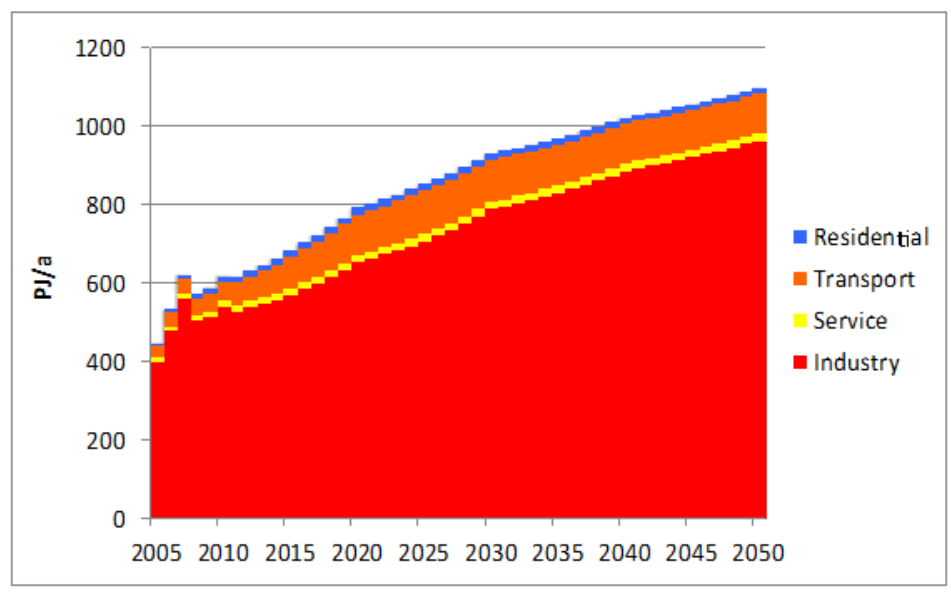

In parallel, structural change is supposed to occur, thus non-energy intensive industries and the service sector would grow stronger than others. Nevertheless, energy intensive industry would still 
exist in Wuxi in 2050 and maintain their production, but with a lower share in GDP. Figure 5 shows the final energy demand of industry, differentiated per energy carrier.

In our CPS there is only little advancement in industrial energy efficiency after 2020, however, the overall energy intensity of the sector is supposed to decline due to structural changes within industry and not due to an improvement of technical processes.

Due to the economic growth, an energy carrier shift to electricity and a phase-out of electricity imports, emissions from electricity generation would be of even more importance than today in the CPS. Total local electricity demand and production in Wuxi is shown in Figure 7.

Figure 7. Electricity production and demand. Source: Wuxi Statistical Yearbook (WMBS) [2], Wuppertal Institute (WI) (projection).

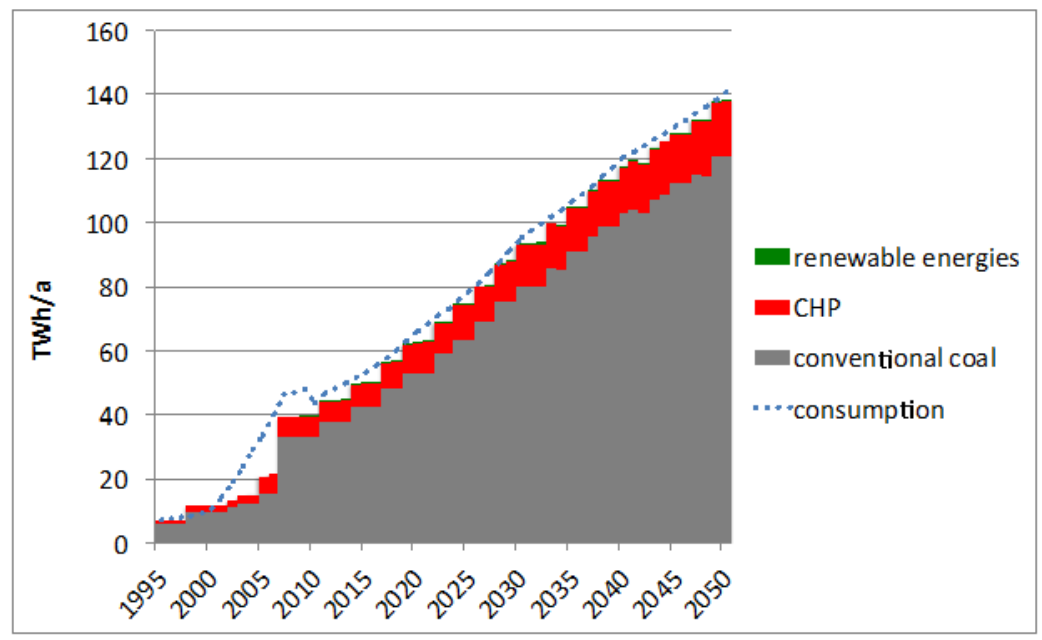

Although in the scenario the intensity targets are supposed to be achieved, this would not lead to absolute emission reductions, as the projected growth would over-compensate the relative reduction. In the CPS, the old energy intensive industries could even keep up their high emission levels while the new industries' additional demand for electricity would result in higher emissions of the power plants (Figure 8).

Figure 8. Total $\mathrm{CO}_{2}$ emissions in the Current Policy Scenario. Source: Wuxi Statistical Yearbook (WMBS) [2], Wuppertal Institute (WI) (projection).

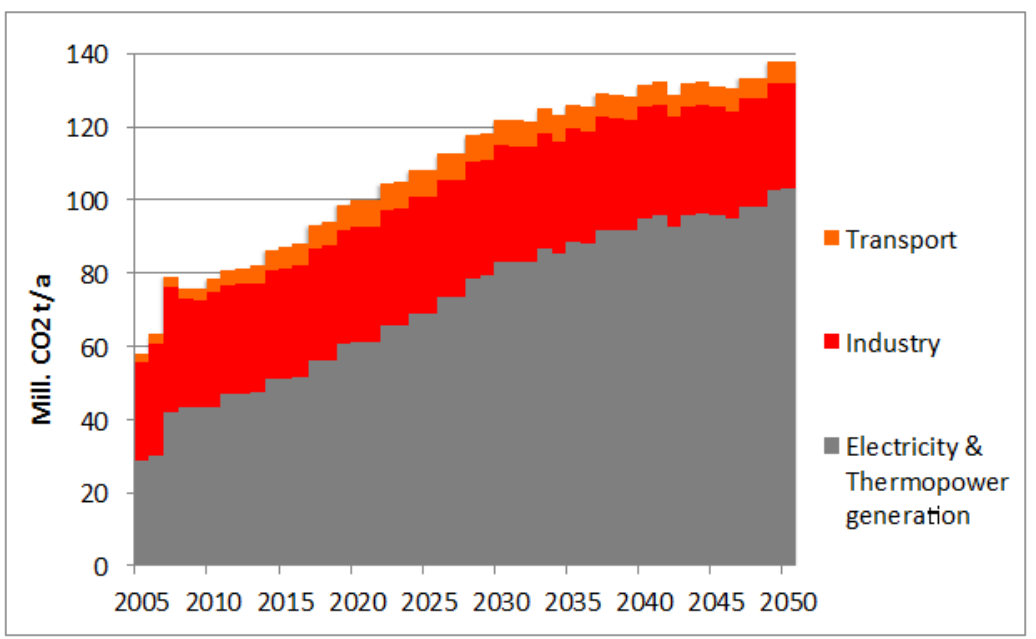


Direct per capita $\mathrm{CO}_{2}$ emissions in Wuxi were 9.7 tons per capita in 2005, which is already above the Chinese average of 7.2 tons in 2011 [15]. According to the CPS, this will more than double to about 23.6 tons in 2050 .

Regarding 2 tons of $\mathrm{CO}_{2}$ per capita as a target in 2050 the gap is quite clear, even if Wuxi claims $\mathrm{CO}_{2}$ "credits" to some extent, as its share in the Chinese production of $\mathrm{CO}_{2}$ intensive products like steel, cement or caustic soda is higher than its population share.

In the forthcoming work of LCFC project, Low Carbon Scenarios shall set more ambitious paths to reduce the emissions in Wuxi. Hence, two further scenarios shall be developed: a "Low Carbon Technology Scenario", which is supposed to show an accelerated use of low carbon technologies especially after 2020 and an "Extra Low Carbon Scenario", which will be designed as a target scenario where ambitious climate protection targets are met by additionally using non-technical measures and behavioral change.

\subsection{Resource Use}

For the energy transformation and the residential building sector, the current status quo, as well as the future material and water flows, have been analyzed and modeled, combining two methods of material flow analysis.

For electricity and heat production not only the direct use of coal in Wuxi is relevant, but also the indirect material flows associated with the extraction, i.e., the ecological rucksack. A high share of the materials and water flows resulting from electricity and heat consumption in Wuxi occur elsewhere, like the resources needed for imported electricity. In 2009 the total material flow sums to 60 million tons. More than 5 times higher is the associated water consumption (332 million tons; 1 ton of water $=$ 1 cubic meter of water). These figures will significantly increase under the assumptions of the CPS.

In 2005, Wuxi's residential buildings represented a stock of 464 million tons of materials. Further increase in population and living standards lead to an increasing building stock. At the same time, older buildings, which have far shorter "life expectancy" than European buildings, are demolished and replaced by bigger housings. Thus, the related demand for construction materials and disposal of building waste also needs to be considered and will be highly significant in both near- and long-term. More details on the resource use can be found in the comprehensive background report to the study [3].

\section{Conclusions}

The picture we get from the analysis is impressive in a manifold manner. From a European perspective, the geographic boundaries and economic structure of Wuxi reach beyond "normal" city dimensions, and so do the emissions. If Wuxi would be counted as a country, it would be among the 50 countries with highest $\mathrm{CO}_{2}$ emissions in the world.

Wuxi has several direct emission sources, especially in the industrial sectors, which are almost immeasurable, meaning that due to the high number of complex industry processes and limited data on these processes, only the direct carbon dioxide emissions could be quantified in the inventory, while for most of the other process-related emissions and so-called "Kyoto-gases", only some qualitative assessments could be given. To be able to monitor the future GHG emissions (of direct emissions 
within the boundaries of Wuxi), not only the establishment of a regular inventory reporting is recommended, it would also be important to improve data quality and calculation methodologies according to local conditions, especially for non- $\mathrm{CO}_{2}$ sources like waste disposal and agriculture, but also for process-related emissions, there is high improvement potential for data and methods.

To help Wuxi focus on the most relevant sources in future low carbon measures, we identified key sectors, based on the current greenhouse gas emissions, also taking into account the relevance for regional policies, vulnerability to climate change and future trends. A number of nine broad key sectors that cover more than $90 \%$ of Wuxi's $\mathrm{CO}_{2}$ emissions were selected. Behind the dominant power and heat sector, most of the key sectors are industrial sectors (iron and steel, chemical, non-metallic minerals, etc.) with high energy demand. This huge demand is not only linked to the traditionally energy intensive industries, but also to the high need for electricity in other upcoming "modern" industry sectors, in the increasing service sector as well as in the residential sector. In addition, the construction sector is relevant, due to the high material/resource uses and the increasing electricity demand for cooling and heating purposes. The final selected relevant sector was road transport, which has increased tremendously (the number of private cars in Wuxi has increased 20-fold since 2000) and is supposed to carry on in the next decade.

Due to the higher electricity needs and higher production capacities within the city in Wuxi's future outlined by the CPS, direct emissions from electricity generation in Wuxi will be of even more importance than today. Wuxi's goal of reducing $\mathrm{CO}_{2}$ intensity by 50\% until 2020 compared to 2005 is a good starting point, but as can be seen in the CPS, it is by far insufficient to ensure that Wuxi will be a city with low emission levels. Despite the relative reduction of energy intensity (related to local GDP), the projected economic growth will overcompensate the relative reduction and no absolute emission reductions will occur.

Looking at the per capita emissions, the dimensions become even more apparent. In 2005 Wuxi's per capita emissions had been around 9.7 tons $\mathrm{CO}_{2}$ per year. This is already above the average Chinese emissions of 7.2 tons (in 2011) and far above discussed average global emissions of 2 tons $\mathrm{CO}_{2}$ per capita per annum.

Although the current discussions on climate change, mitigation and low carbon strategies mainly focus on greenhouse gas emissions and their impacts, the environmental pressures from the demand for coal and other resources, like construction materials and water flows, must not to be forgotten. In the long-term they are as relevant (or even more) for the sustainability of the global environment. About double the material flow related to the coal combusted in Wuxi needs to be added to account for the extraction of this fossil fuel. Considering the same assumptions as the CPS for future development, the high increase of electricity needs and imports is supposed to correspond with increasing resource demands. Furthermore, increasing population and living standards lead to an increasing building stock. Thus, the related construction and disposal of building waste also needs to be considered, and is expected to retain high significance.

In order to understand past and future changes of Wuxi's regional vulnerabilities to climate change, we analyzed climatic parameters and the changes that have been observed and projected. The temperature risk will increase due to climate change, i.e. the frequency and magnitude of heat waves and maximum temperatures will increase. Although the risk of economic losses due to temperature 
hazards is relatively low today, it might dramatically rise in the future. Linked to the temperature changes in combination with the need for higher living standards are the above-mentioned increased needs for cooling and heating of residential buildings.

Of greater importance for economic development is the risk of flood and heavy rains, despite the fact that this hazard did not, and will most probably not, severely change. However, due to an increasingly dense infrastructure, Wuxi's vulnerability to floods and heavy rainfall is projected to grow. Therefore, it is recommended to increase Wuxi's coping capacity against such weather events in order to reduce impacts of temperature and flood hazards and thereby reduce the city's vulnerability.

Overall, it is concluded that although Wuxi's city government has set reduction targets and developed a low carbon plan, the projection results show that more ambitious efforts are needed to overcome the challenges faced and reduce the total $\mathrm{CO}_{2}$ emissions and material uses. The results of the analysis above try to give a full picture of the real status quo and possible future development under current policy conditions, which is crucial basis set the path for a low carbon future in the city of Wuxi and to develop a sound an ambitious low carbon roadmap in the coming years.

\section{Remark}

We would like to remark that the data used is in parts incomplete and bears uncertainties that need to be kept in mind. This is also true for the data used in the scenarios, for the calculation of the material flows as well as for the models used to determine the climate change vulnerability.

\section{Acknowledgments}

The authors would like to thank Marco Gemmer and Jiang Tong of China Meteorological Administration (CMA), National Climate Centre (NCC), Andreas Oberheitmann of China Environment Research (CER) as well as Wang Haoping and Wang Can of Tsinghua University, Research Centre for International Environmental Policy (RCIEP) for their cooperation and contributions to the project. A special thanks goes to Urda Eichhorst of GIZ and formerly Wuppertal Institute for Climate, Environment and Energy, Ren Hongyan and Sui Yingying of Wuxi Low Carbon Center (WLCC) for the fruitful cooperation and helpful information. In addition, we would like to thank the city of Wuxi for the good cooperation.

We also would like to acknowledge the financial support of the LCFC project by Stiftung Mercator.

The paper is based on the summarized background report on Work package 2 report on "Integrated Status Quo and Trends Assessment in Wuxi” [3] where details on the results can be found.

\section{Conflict of Interest}

The authors declare no conflict of interest. The paper has been presented online at the $2^{\text {nd }}$ World Sustainability Forum (WSF) and invited for the Special Issue for the same forum.

\section{References}

1. United Nations Human Settlements Programme. Cities and Climate Change (Global Report on Human Settlements 2011); Earthscan/Routledge: London, UK, 2011. 
2. Wuxi Municipal Bureau of Statistics (WMBS). Wuxi Yearbook 2001-Wuxi Yearbook 2010; China Statistics Press: Beijing, China, 2010. Available online: http://www.wxtj.gov.cn/ tjxx/tjsj/tjnj//index.shtml (accessed on 28 March 2011).

3. Dienst, C.; Höller, S.; Saurat, M.; Schneider, C.; Xia-Bauer, C.; Oberheitmann, A.; Fischer, T.; Gemmer, M.; Jiang, T.; Wang, C.; et al. WP2 Report-Integrated Status quo and Trends Assessment in Wuxi; Overview of WP2 results Low Carbon Future Cities Report, Wuppertal. 20. Available online: http://www.lowcarbonfuture.net (accessed on 8 May 2013).

4. Environment Canada: Greenhouse Gas Emissions Quantification Guidance. Available online: http://www.ec.gc.ca/ges-ghg/default.asp?lang=En\&n=DDE56C0F-1 (accessed on 26 April 2011).

5. Intergovernmental Panel on Climate Change (IPCC). IPCC Guidelines for National Greenhouse Gas Inventories; IGES: Hayama, Japan, 2006; Volume 1-5.

6. Marland, G. Emissions accounting: China's uncertain $\mathrm{CO}_{2}$ emissions. Nat. Clim. Change 2012, 2, 645-646.

7. Reuters. China Emissions Study Suggests Climate Change Could Be Faster than Thought. Available online: http://www.reuters.com/article/2012/06/10/us-china-emissions-idUSBRE859 0AD20120610 (accessed on 28 September 2012).

8. Jiang, K.J.; Hu, X.L.; Zhuang, X.; Liu, Q.; Zhu, S.L. China's Energy Demand and Greenhouse Gas Emission Scenarios in 2050. Adv. Clim. Change Res. 2008, 4, 296-302.

9. $\mathrm{Wu}, \mathrm{K} . \mathrm{C}$. The analysis on the features, trend and strategies of population ageing. Available online: http://web.cenet.org.cn/web/wdr1960/index.php3?file=detail.php3\&nowdir=\&id=105504 (accessed on 8 May 2013).

10. Gemmer, M.; Fischer, T.; Jiang, T. Changes in Climate Parameters and Vulnerability Aspects-WP 2: Status Quo and Trends Assessment of Climate Change Impacts and Vulnerability, Greenhouse Gas Emissions and Hot-Spot Analysis of Resource Use in Wuxi, 2012. Available online: http://www.lowcarbonfuture.net/wp-content/uploads/2012/07/LCFC_doc16_0en_wp2_climate_ parameters_vulnerabilities.pdf (accessed on 28 September 2012).

11. Roeckner, E.; Bäuml, G.; Bonaventura, L.; Brokopf, R.; Esch, M.; Giorgetta, M.; Hagemann, S.; Kirchner, I.; Kornblueh, L.; Manzini, E.; et al. The Atmospheric General Circulation Model ECHAM 5. PART I: Model Description; MPI Report No. 349; Max-Planck-Institute for Meteorology: Hamburg, Germany, 2003.

12. Collier, M.A.; Dix, M.R.; Hirst, A.C. CSIRO Mk3 Climate System Model and Meeting the Strict IPCC AR4 Data Requirements. In Proceedings of the MODSIM07 International Congress on Modeling and Simulation: Land, Water \& Environmental Management: Integrated Systems for Sustainability, Christchurch, 10-13 December 2007; Modeling and Simulation Society of Australia and New Zealand, Canberra, Australia, 2007; pp. 582-588.

13. Ritthoff, M.; Rohn, H.; Liedtke, C. Calculating MIPS: Resource Productivity of Products and Services; Wuppertal Inst. for Climate, Environment and Energy: Wuppertal, Germany, 2002; Wuppertal Spezial 27.

14. Schmidt-Bleek, F. MIPS Re-visited. Fresenius Environ. Bull. 1993, 2, 407-412. 
15. Olivier, J.; Janssens-Maenhout, G.; Peters, J. Trends in Global $\mathrm{CO}_{2}$ Emissions-Report 2012; PBL Netherlands Environmental Assessment Agency Institute for Environment and Sustainability (IES) of the European Commission's Joint Research Centre (JRC): The Hague, The Netherlands, 2012.

(C) 2013 by the authors; licensee MDPI, Basel, Switzerland. This article is an open access article distributed under the terms and conditions of the Creative Commons Attribution license (http://creativecommons.org/licenses/by/3.0/). 